\title{
Sugar Sweetened Beverage Consumption among Primary School Students: Influence of the Schools' Vicinity
}

\author{
Alexandre Lebel, ${ }^{1,2}$ Pascale Morin, ${ }^{3}$ Éric Robitaille, ${ }^{4}$ Benoit Lalonde, ${ }^{2}$ \\ Ramona Florina Fratu, ${ }^{2,4}$ and Sherri Bisset ${ }^{2}$ \\ ${ }^{1}$ Graduate School of Land Management and Regional Planning, Laval University, 2325 Rue des Bibliothèques, \\ Quebec, QC, Canada G1V 0A6 \\ ${ }^{2}$ Evaluation Platform on Obesity Prevention, 2725 Chemin Sainte-Foy, Quebec, QC, Canada G1V 4 G5 \\ ${ }^{3}$ University of Sherbrooke, Faculty of Physical Activity Sciences, 2500 Boulevard de l'Université, Sherbrooke, QC, Canada J1K 2R1 \\ ${ }^{4}$ Quebec's National Institute of Public Health, 190 Boulevard Crémazie Est, Montréal, QC, Canada H2P 1E2
}

Correspondence should be addressed to Alexandre Lebel; alebel@criucpq.ulaval.ca

Received 15 June 2016; Accepted 30 August 2016

Academic Editor: David Vlahov

Copyright (C) 2016 Alexandre Lebel et al. This is an open access article distributed under the Creative Commons Attribution License, which permits unrestricted use, distribution, and reproduction in any medium, provided the original work is properly cited.

The purpose of the research was to explore the associations between the characteristics of schools' vicinity and the risk of sugar sweetened beverage (SSB) consumption in elementary students. Findings exposed an important variation in student's SSB consumption between schools. Schools with a lower socioeconomic status or in a densely built environment tend to have higher proportion of regular SSB drinkers. These characteristics of the school's vicinity partly explained the variation observed between them. We estimated that a student moving to a school with a higher proportion of SSB drinkers may increase his/her chances by $52 \%$ of becoming a daily consumer. Important changes in dietary preferences can occur when children are in contact with a new social environment. Findings also support the idea that dietary behaviors among children result from the complex interactions between biological, social, and environmental factors.

\section{Introduction}

Obesity, a level of body fatness associated with risk of developing chronic diseases, such as diabetes, dyslipidemias, and arterial hypertension, has become a serious health concern around the world [1]. Over the last 30 years, the rate of children suffering from obesity has increased significantly. In the United States, $12.4 \%$ of preschoolers were estimated to be obese, and this prevalence increased to $20.8 \%$ by the age of 14 [2]. In England, the prevalence of obesity was estimated to be $14 \%$ for both boys and girls aged 2-15 years [3]. In Canada, the prevalence was estimated to be $11.6 \%$ for children in 2010 [4].

Several hypotheses have been proposed for the rapid increase in obesity among children living in occidental countries. On the one hand, fitness levels of children have declined significantly since 1981, regardless of age or gender [5]. At ages 5-11, only 7\% of children reach the recommended guidelines of 60 minutes or more of daily physical activity to achieve substantial health benefits [6,7]. Aside from physical education classes, organized activities such as soccer, swimming, and football as well as active transportation to school and free play should be considered in order to reach daily guidelines [8-10].

On the other hand, overconsumption of energy dense foods with low nutritional quality is seen as an important contributor to childhood obesity [11, 12]. Sugar sweetened beverages (SSB) fall into this category of foods that add calories to the diet but are void of vitamins and minerals $[13,14]$. Moreover, since SSBs do not influence appetite, the consumer drinks an additional dose of liquid calories while eating [15]. Convenience and snack food account for $40 \%$ of the total calories consumed by US children, of which $22 \%$ are from sugar sweetened beverages (SSBs) [16]. In the US, low-income persons consume more sugar drinks in relation to their overall diet than those with higher income [17]. SSB consumption is higher among African-American and Hispanic children and adolescents than among whites 
[17]. Consumption is higher among US boys than girls; $70 \%$ of boys aged 2-19 years consume SSBs daily [18]. A metaanalysis of cohort studies found that higher intake of SSB among children was associated with 55\% (95\% CI 32-82\%) higher risk of being overweight or obese compared with those with lower intake [19]. SSB consumption was also associated with type 2 diabetes where individuals are consuming more than 1-2 servings/day and had a $26 \%$ greater risk of developing type 2 diabetes than those consuming less than 1 serving/month [20].

Both theoretical and empirical evidence confirm the important role the environment plays in children's health behaviors in general [21-23] and obesity in particular [24, 25]. While most evidence on obesity related dietary behaviors in youth has focused on the influence of sociocultural and economic factors at the household level [21], more recently studies have shown that built and food environments associate with physical activity, healthful eating, and obesity [22, 26-28]. In particular, access to low nutritional foods and a lack of space for outdoor recreation are related to higher rates of obesity in boys and girls [29, 30]. Multilevel models, inspired from social ecological theory, posit that childhood obesity is influenced by energy intake and expenditure patterns embedded within familial and wider community contexts [31]. For example, associations between obesity and the built environment vary by gender, age, socioeconomic status, and population density, while the relationship between neighbourhood built environment and youth obesity risk is mediated by socioeconomic status (SES) [32]. Schools can indeed be located in an environment that discourages physical activity or promotes reliance on convenience stores and fast food restaurants [5, 33-36].

There is some evidence supporting the existence of a relationship between the characteristics of the environment surrounding schools and students' SSB consumption [37, 38]. A Canadian study found SSB consumption to be lower in schools located in communities with a postsecondary education institution $(\mathrm{OR}=0.89 ; p=0.006$ comparing no consumption to one), lower in schools reporting to limit availability of SSB $(\mathrm{OR}=0.85 ; p=0.02)$, and lower among girls $(\mathrm{OR}=0.49 ; p<0.001)$ but not significantly different between the school settings (rural, suburban, or rural) [39]. However, substantial heterogeneity in study designs, methods, and measurement tools makes it difficult to draw firm conclusions [37]. Many recent studies have cast doubt on the effect of the environment on child dietary behavior $[5,32,40-42]$. In this respect, many other studies suggest that consumption of SSB in schools is insufficient to predict overall consumption [5, 18, 40, 41, 43] and may be associated with other environmental influences. However, environmental influences of SSB consumption on children, beyond the internal environment of the school, are relatively unknown and need to be explored further to inform public policies and interventions for youth health [12, 40-42, 44]. The purpose of this study was to explore the association between characteristics of the schools' vicinity and the risk of SSB consumption for all primary school students living in a Canadian metropolitan area.

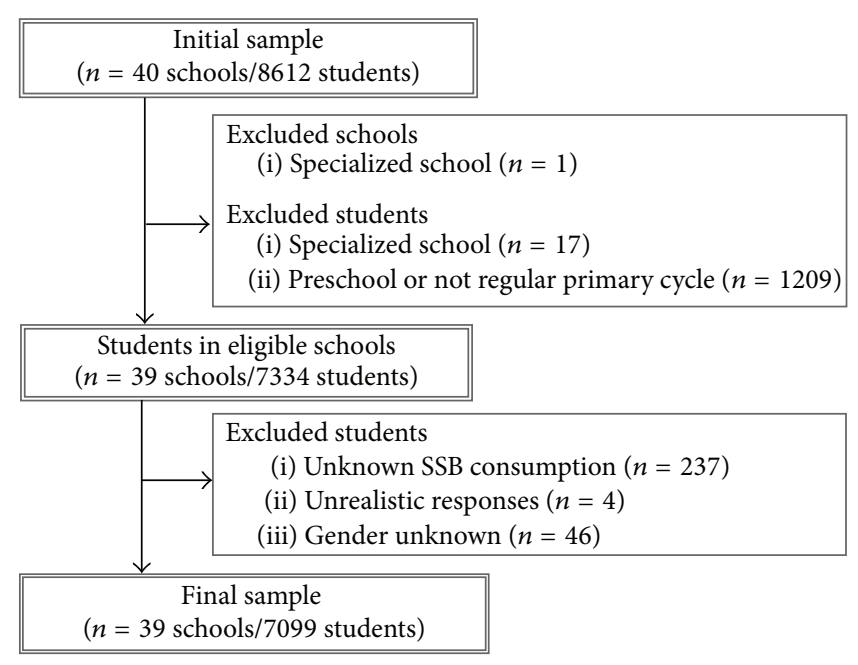

FIGURE 1: Flowchart of exclusion criteria for schools and students.

\section{Materials and Methods}

2.1. Data-Collection Procedure. The metropolitan area of Sherbrooke is located in the southern part of Quebec close to the USA border. It is the 19th largest urban area in Canada, with a population of approximately 200,000 people in 2011. With the help of the Sherbrooke Regional School Board (SRSB), we undertook an exhaustive survey of 40 public primary schools (children aged 5 to 12 years) in 20072008. The main purpose of this survey was to assess the most frequent youth behaviors related to diet and physical activity in order to develop school and community health interventions.

An explanatory letter, a self-administered questionnaire, and a return envelope were sent to the parents of all students registered in a SRSB school. The self-administered questionnaire queried eating behaviors and physical activity. Most of the questionnaire items were inspired from previous reliable surveys $[45,46]$. The complete questionnaire was submitted to ten content experts for face validity testing. After minor adjustments, ease of completion and feasibility were assessed with a convenience sample of 40 parents of children at two primary schools. The final version of the questionnaire comprised 42 questions and took approximately 40 minutes to complete. Details about the collection procedure have been published elsewhere [47].

2.2. Study Population. All SRSB schools were solicited. In order to obtain a homogeneous sample, smallest schools (<40 students) and specialized schools (e.g., for disabled students) were not part of our study population. Every school participated and the parents of 8612 students completed the self-administered questionnaire, providing a participation rate of $79 \%$.

2.3. Participants and Outcome. Figure 1 presents the detailed eligibility criteria. A total of 7099 students from 37 schools in 39 buildings were kept for the analyses (two schools were actually operating two separate buildings). For our study 
TABLE 1: Characteristics of students and schools areas.

\begin{tabular}{lc}
\hline & Frequency \\
& $n(\%)$ \\
\hline Outcome & \\
Sugar sweetened beverages (SSBs) & $1060(14.9)$ \\
At least one SSB each day & $6039(85.1)$ \\
Less than one SSB each day & \\
\hline Students $(n=7099)$ & \\
Gender & $3543(49.9)$ \\
Girls & $3556(50.1)$ \\
Boys & \\
Primary school cycle & $2264(31.9)$ \\
1st cycle (6-7 years old) & $2343(33.0)$ \\
2nd cycle (8-9 years old) & $2492(35.1)$ \\
3rd cycle (10-11 years old) & \\
Cultural origin & $6138(86.5)$ \\
Quebec French & $717(10.1)$ \\
Others & $244(3.4)$ \\
Unknown & \\
Physical activity & $11(28.2)$ \\
Organized & $9(23.1)$ \\
None & \\
Unknown & $13(3309(32.5)$ \\
\hline Schools $(n=39)$ & $3859(54.4)$ \\
School socioeconomic index (SSEI) & $931(13.1)$ \\
High & \\
Middle & \\
Low & \\
Urban density & \\
Lowest & \\
High & \\
\hline & \\
Highest & \\
\hline
\end{tabular}

purpose, each building is kept independent and will be referred to as a school.

2.3.1. Outcome Variable. The outcome variable was a dichotomous indicator of the consumption of at least one sugar sweetened beverage (SSB) per day as compared to less than one SSB per day. Drinking over one SSB per day has been associated with individuals' health status in several recent studies $[35,48,49]$. SSB was measured by consumption of fruit flavored drinks, regular soft drinks, slush, sport drinks, and energy drinks on a 5-point scale ranging from never to several times per day (100\% fruit juice was excluded). The individual-level measurement of SSB consumption frequency was adapted from the Canadian Health Measures Survey (CHMS) and the Social and Health Survey on Children and Teenagers (SHSCT). Overall 14.9\% reported to drink at least one SSB each day (Table 1).

2.3.2. Individual Covariates. Since SSB consumption is often associated with individual characteristics $[39,50]$, covariates include gender, academic cycle, cultural origin, and the participation in organized physical activities. No information was available on the household. Table 1 presents the descriptive statistics of the final sample. The sample included the same proportion of girls and boys and approximately a third of students in each of the three academic cycles with slightly more students in the 3 rd cycle (10 to 12 years old). The majority of students were Quebec native and francophone $(86.5 \%)$. Most children were reported to participate in organized physical activities (54.4\%).

2.3.3. School-Level Variables. Reported associations between children's dietary behaviors and school neighbourhood measurements presented substantial heterogeneity in the literature $[22,27,28,32,51]$. It is important to recall, however, that the contextual influences on child's behaviors are not necessarily direct and causal; it is rather suggested to be considered as a risk regulator. They are not themselves risks but are the conditions that regulate or control exposure probabilities to behaviors that lead to disease [52]. Consequently in this study, the selected contextual variables included not only measurements typically associated with SSB consumption (the access to convenience stores and fast food restaurants), but also other contextual characteristics more broadly associated with children's healthy lifestyle such as a pedestrian friendly environment measured by the presence of green spaces and the walkability of streets [53].

More precisely, six contextual variables measuring characteristics of the built environment surrounding the schools were included in our study: (1) convenience stores density, (2) fast food restaurant density, (3) closest convenience store, (4) closest fast food restaurant, (5) degree of vegetation cover, and (6) street walkability. Data to create these measures were derived from a geographical information system (GIS) using ArcGIS 10 (ESRI Inc., Redlands, CA, USA) software and its Network Analyst extension. These contextual measurements referred to the proximal environment of each school instead of the administrative boundaries of their neighbourhood. In this way, schools measurements were directly comparable. Two global contextual variables were created from these six measures using a principal components procedure. Finally, one school-level variable measuring school socioeconomic index was included in our model.

Density measures of convenience stores and fast food restaurants, degree of vegetation cover, and walkability relied upon the construction of 750 meters of (approximately half a mile) sausage network buffer around the school buildings [54]. Closest access to convenience stores and fast food restaurants was calculated using "Adresses Québec" (http:// adressesquebec.gouv.qc.ca/) network file (excluding highway network) and including pedestrian trails from the components of regional geographic use layer. Detailed information on their construction is reported elsewhere [55].

Convenience Stores Density. Convenience stores were identified through the Quebec Ministry of Agriculture, Fisheries and Food 2009 sales licenses as well as an automated and manual search by keywords. The convenience store indicator refers to establishments comprised within an area less than 
TABLE 2: The walkability index components.

\begin{tabular}{llll}
\hline Measure & Definition & Equation & Data source \\
\hline $\begin{array}{l}\text { Residential } \\
\text { density }\end{array}$ & Number of dwellings per hectares & $\begin{array}{l}\text { Dwellings number/hectares number of } \\
\text { buffer zone } \\
\begin{array}{l}\text { Density of } \\
\text { destinations }\end{array}\end{array}$ & Number of destinations per square kilometer \\
$\begin{array}{l}\text { Density of } \\
\text { intersections }\end{array}$ & Number of intersections per square kilometer & $\begin{array}{l}\text { Quebec assessment } \\
\text { roll } \\
\text { Intersections number/square kilometer of } \\
\text { buffer zone }\end{array}$ & $\begin{array}{l}\text { Quebec assessment } \\
\text { roll } \\
\text { Adresses Québec } \\
\text { road network }\end{array}$ \\
$\begin{array}{l}\text { Land-use mix } \\
\text { foterogeneity of distribution of square meter } \\
\text { recreational, and institutional services }\end{array}$ & Entropy based index & $\begin{array}{l}\text { Quebec assessment } \\
\text { roll }\end{array}$ & \\
\hline
\end{tabular}

TABLE 3: Correlation pattern and explained variance of built environment variables by PCA factors.

\begin{tabular}{|c|c|c|c|c|c|}
\hline \multirow{2}{*}{ Built environment variable } & \multirow{2}{*}{ Mean (SD) } & \multicolumn{2}{|c|}{ Correlation pattern } & \multirow{2}{*}{ Variance $(\%)$} & \multirow{2}{*}{ Underlying concept } \\
\hline & & Factor 1 & Factor 2 & & \\
\hline $\mathrm{Nb}$. fast foods & $1.8(2.3)$ & 0.894 & -0.093 & \multirow{4}{*}{68.8} & \multirow{4}{*}{ Urban density } \\
\hline $\mathrm{Nb}$. convenience stores & $1.5(1.1)$ & 0.871 & -0.225 & & \\
\hline Walkability $^{\dagger}$ & $0.2(1.9)$ & 0.825 & -0.411 & & \\
\hline $\mathrm{NDVI}^{\dagger \dagger}$ & $0.4(0.1)$ & -0.854 & 0.379 & & \\
\hline Distance to closest convenience store (m) & $1653(2800)$ & -0.220 & 0.959 & \multirow{2}{*}{19.1} & \multirow{2}{*}{ SSB sources proximity } \\
\hline Distance to closest fast food restaurant (m) & $877(1619)$ & -0.285 & 0.940 & & \\
\hline
\end{tabular}

${ }^{\dagger}$ Walkability index: a higher value of the walkability index suggests a pedestrian friendly environment.

${ }^{\dagger \dagger}$ Normalized difference vegetation index: the NDVI values extend from -1 to $1 ;-1$ expressed a total lack of vegetation, while 1 would report a dense forest cover.

400 square meters, which sell food of all kinds, with or without gasoline sales. The density of convenience stores was computed by estimating the number of stores by $\mathrm{km}^{2}$.

Fast Food Density. The fast food restaurants indicator combined the "snack," "takeout restaurants," and "fast food restaurants" categories, as identified by the Quebec Ministry of Agriculture, Fisheries and Food 2009 sales licenses. These restaurants typically offer limited or no table service and a variety of SSB. The density of fast food restaurants was computed by estimating the number of such restaurants by $\mathrm{km}^{2}$.

Closest Convenience Store. The distance to the school's closest convenience store was computed on the pedestrian road network.

Closest Fast Food Restaurant. The distance to the school's closest fast food restaurant was computed on the pedestrian road network.

Vegetation Cover. The normalized difference vegetation index (NDVI) was estimated using a mosaic of 30 meters of spatial resolution images. Images were taken with the Landsat Satellite Enhanced Thematic Mapper Plus (ETM +) sensor in 2011. Cloud presence was minimized by the combination and cutting several scenes. The NDVI values extend from -1 to 1 ; -1 indicated a total lack of vegetation, while 1 would refer to a dense forest cover. Extraction raster file cell values operations were performed using the Geospatial Modeling Environment software [56].
Street Walkability. The walkability index was computed based on four school-level measurements: residential density; destinations density; street connectivity; land-use mix. These indicators were objectively determined for each school [57, 58] (Table 2). Standardized $z$-scores of each measure were summed to construct a walkability index $[59,60]$. A higher value of the walkability index suggests a pedestrian friendly environment.

Global Indexes. In order to consider schools' neighbourhood built environment measurements more globally, we produced two synthesised contextual indicators issued from a principal component analysis (PCA) $[61,62]$. The six built environment variables were introduced in a PCA and produced two uncorrelated factor scores with an eigenvalue higher than 1 (i.e., a significant part of the variance of all six variables was explained by the factor). The strength and the sign of the correlations were used to interpret the meaning of the underlying concept for each factor (Table 3). Interpretation suggested the first factor would be related to the "urban density" or the physical accessibility to food resources and account for about $69 \%$ of the variance of the six variables. The other factor refers to the "food sources proximity" and explained $19 \%$ of the variance.

School Socioeconomic Index. The school socioeconomic index (SSEI) was computed with two variables issued from the 2006 Canadian census by the Quebec Ministry of Education [63]: the education level of the mother and the inactivity of the parents, and it was adjusted for school year 20072008 population. These two variables were chosen since they 
TABLE 4: Sequential modeling strategy.

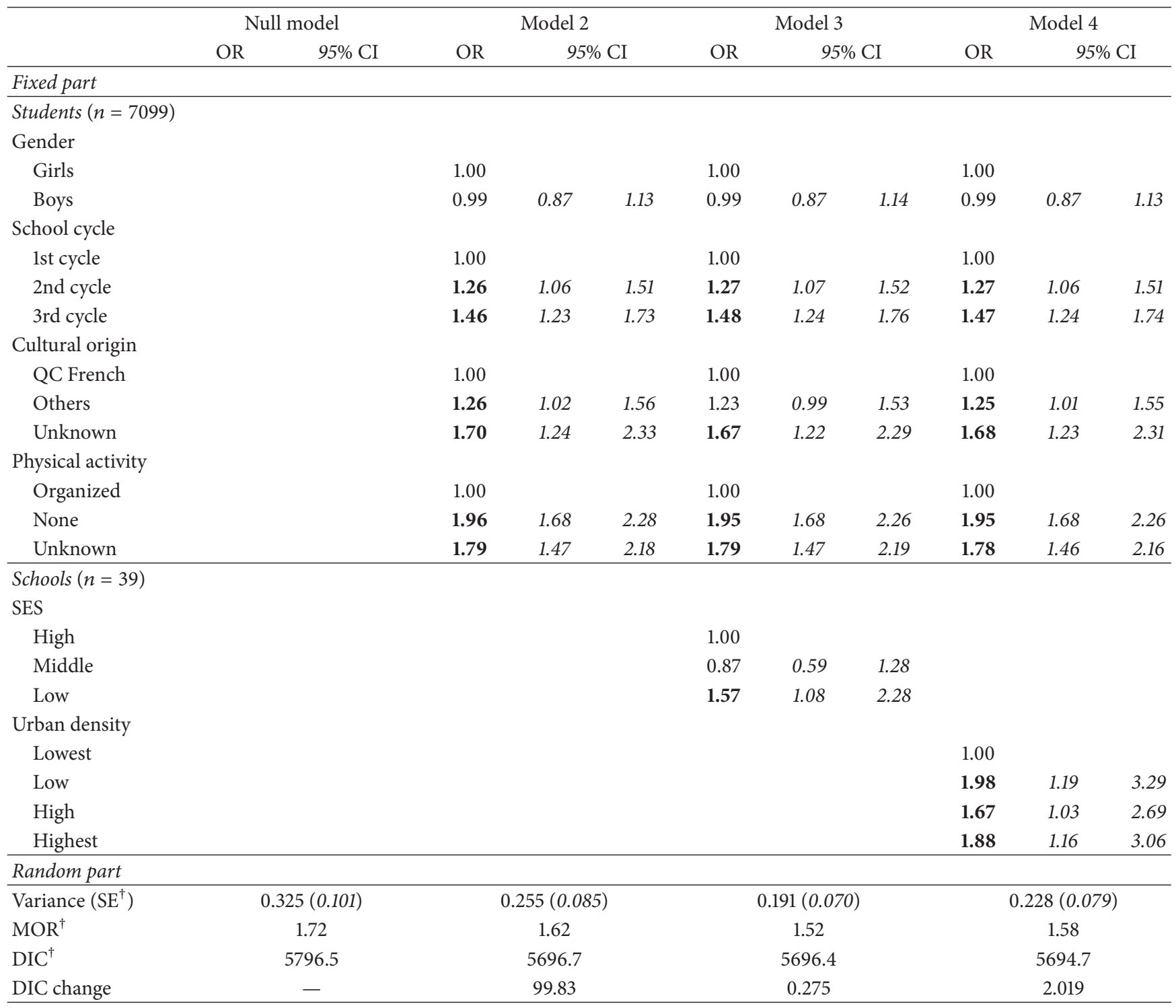

${ }^{\dagger}$ SE: standard error, MOR: median odd ratio, and DIC: deviance information criterion.

showed the highest correlation with youth academic failure [64]. The SSEI is calculated for all schools of the province and is typically distributed in deciles, from 1 (10\% most privileged) to 10 (10\% most deprived). According to their provincial score, the 39 schools were reclassified into terciles to distinguish high and low SES among Sherbrooke's schools (Table 1). School-level measurements and factor scores were divided into quartiles to control for the nonnormality of distributions and the nonlinear associations with child SSB consumption.

2.4. Data Analysis. Multilevel logistic modeling procedures were used to assess whether variation in SSB consumption could be associated with the neighbourhood's characteristics surrounding the school. The models were fitted using Bayesian estimation procedures as implemented via Monte Carlo Markov Chain (MCMC) methods using
Metropolis-Hastings algorithm in MlwiN 2.25 [65]. A fourstep sequential modeling strategy was adopted in order to explain the outcome variation between schools (Table 4).

Model 1 is a two-level null model. This controls for the nonindependence of observations within schools and estimates the mean correlation of students' SSB consumption associated with the school, without taking into account individual or school characteristics. The null model shows if there is a significant variation of SSB consumption between schools.

Model 2 is a two-level model which includes characteristics of students. This allows estimating the mean correlation of students' SSB consumption associated with the school while controlling for individuals' characteristics. This model determines if the variation of SSB consumption between schools is simply a result of the individual characteristics of students (gender, age, cultural origin, and physical activity). 
The reference categories were girls, in 1st cycle, from a FrenchCanadian cultural origin, who participated in organized physical activities. Since the objective of the study was to explore contextual influences on students SSB consumption, Model 2 was used to compare fixed and random parameters in order to observe the effect of contextual measurements while controlling for individual characteristics.

Model 3 is an extension of Model 2 but includes schools' SSEI. The reference category was the schools in the lowest SSEI tercile (i.e., high SES). This model determines if the schools' SES explains the variation of SSB consumption between schools.

Model 4 is an extension of Model 2 but includes schools' neighbourhood measurements. At this step, all six schoollevel built environment measures and the two global indexes were individually tested (8 different models) in order to identify which aspects of the school vicinity may contribute to explain the between-school variation of SSB consumption. This procedure is essential because even if we analysed the entire population of Sherbrooke's primary schools, our second-level distribution includes only 39 observations. Consequently, the variation between second-level observations is limited and does not allow the inclusion of many secondlevel variables simultaneously. Moreover, second-level measurements based on geographic location often face multicolinearity problem $[62,66]$. Nevertheless, analysing them separately provides valuable information on their respective contribution.

All models present the odds ratio (OR) of SSB consumption with its $95 \%$ confidence interval (CI) for each characteristic considered (fixed part). The between-school variance structure (random part) was analysed using the median odd ratio (MOR). The MOR was considered significant when the school-level variance was at least 1.96 times higher than its standard error (SE). The MOR can be interpreted as the increased chances a pupil has to drink at least one SSB per day, if this student was moving from a school with a lower chance to a school with a higher chance of a daily SSB consumption. The epidemiologic interpretation of the MOR is more straightforward than other random parameters issued from multilevel modeling since it can be directly compared to a regular OR and thus evaluate if the school-level effect is more or less important than other variables included in the model [67].

We used the deviance information criterion (DIC) to compare the models goodness of fit. The DIC is a measure of data fitting which considers the number of model parameters [68]. A high DIC for the number of parameters suggests a low model performance. A small DIC difference $(\leq 2)$ between two models shows equivalency while a larger difference indicates a significant improvement [69].

\section{Results}

The null model considered no variable in the fixed part of the model, while the random part shows a significant variation of SSB consumption between schools. It also revealed that students risk of consuming SSB on a daily basis increased by $72 \%(\mathrm{MOR}=1.72)$ if they would move from a school which had a lower rate of SSB consumption to one which had a higher rate of SSB consumption.

Model 2 introduced four individual-level indicators. We observed no significant difference between girls and boys. Older students and those that were not QC French had higher risk of consuming SSB. Students that did not participate in organized physical activities had almost twice the risk of drinking SSB daily ( $\mathrm{OR}=1.96$; $\mathrm{IC}=1.68-2.28)$ compared to students involved in organized physical activities. This model shows that a typical student registered in a Sherbrooke primary school who drinks SSB on a daily basis would be 10 to 12 years old, not QC French, and does not participate in organized physical activities. Taking individual characteristics into account reduced the school-level variance which brought down the MOR to 1.62. Thus, individuals characteristics were not uniformly distributed between schools and this would explain $10 \%$ of the risk in SSB consumption at the school level. Moreover, considering students' characteristics increased the goodness of fit importantly shown by the DIC difference of 99.33.

Model 3 introduced only one school-level variable, the school socioeconomic index (SSEI); the associations with the individuals' characteristics remained stable. The school's SSEI was significantly associated with students SSB consumption. Schools with the lowest SSEI had an increased risk of $57 \%$ to have more students drinking SSB every day. In the random part, considering the SSEI explained an additional 10\% of risk shown by the MOR but did not significantly increase the goodness of fit (the model is still good but was not improved).

Prior to building Model 4, we individually introduced the six built environment variables and the two global indexes ( 8 different models). None of the built environment measures was significantly associated with SSB consumption. For the two global measurements, only the urban density index issued from the PCA was associated with child's SSB consumption. The association not only was significant but also was shown to be relatively strong with an effect similar to the physical activity level of students. However, no gradient was observed between the level of urban density and SSB consumption; that is, students going to a school with the lowest "urban density" environment (few or no fast food restaurants and convenience stores, with a low street walkability, and a high vegetation cover) had significantly a lower risk to drink SSB than students in the other school environments in Sherbrooke ( $\mathrm{OR}=1.67$ to 1.98$)$. This, however, explained less of the between-school variance $(\mathrm{MOR}=1.58)$ than the SSEI (Model 3) but had a slight increase in the model goodness of fit.

\section{Discussion}

We examined associations between the characteristics of the schools' vicinity and the risk of the SSB consumption in a large sample of primary school students. At the individual level, the prevalence of daily SSB consumption among Sherbrooke's school children was $15 \%$, a relatively low level as compared to what was observed in Europe [70] or in the USA [18]. Individual predictors, age, cultural origin, and physical activity level, were all associated with SSB daily consumption. 
These results are in line with previous research findings showing that individual characteristics are important predictors of SSB consumption, especially age, physical activity, and economic and cultural origin [17]. Unlike other studies [18] we found no association with the gender of students. Together, individual characteristics explained about $10 \%$ of the difference of risk of daily SSB consumption between schools.

At the school level, SSB consumption was also found to vary significantly above students' characteristics. The variation in SSB consumption between schools was explained independently by the SSEI and the urban density where it is located. Students in the lowest SSEI were more likely to drink SSB every day than students in schools with the highest SSEI. The schools' socioeconomic status explained an additional $10 \%$ in the risk of daily SSB consumption between schools. This suggests that, above individual characteristics and the school's socioeconomic status, a Sherbrooke student moving from a school with a lower rate of SSB consumption to a school with a higher rate would typically increase his/her risk by $52 \%$ to daily consume SSB. Although few studies reported SSB consumption between schools, results are in line with the results of Carter and Dubois [71] which suggested that neighbourhood deprivation was more consistently associated with childhood obesity. This finding also recalls that peer behaviors may have an influence on diet among children [72]. Indeed, Freeland-Graves and Nitzke [73] showed that diet preferences and behaviors may change importantly when children are in contact with a new social environment.

Beside the socioeconomic environment of the school, we also explored six contextual characteristics measured within 750 meters of the schools: the number of fast food restaurants, the number of convenience stores, the walkability, the degree of vegetation cover, the distance to the closest fast food restaurant, and the distance to the closest convenience store. Letting individual characteristics constant, none of them were found to have a significant association with SSB consumption. We further explored the combined effect of these measurements and found that students going to schools with the lowest urban density, globally estimated by few or no fast food restaurants and convenience stores in the vicinity, with a low potential of walkability and with an important vegetation cover, may have twice as much as less chances to daily consume SSB than those in other schools (Model 4). As for the socioeconomic environment, this is in line with other studies findings. In a multilevel analysis, Leatherdale et al. [30] found an increased risk of overweight with more fast food retailers around schools. Ogden et al. [17] indicate that a little less than one-half of sugar-drink kilocalories (48\%) are consumed away from home. Of these, $43 \%$ are purchased in stores, $35.5 \%$ in restaurants or fast food establishments, and $1.4 \%$ in schools or day-care settings. Moreover, according to van Hulst et al. [74], who realised a study in a metropolitan Canadian city, supermarkets, fast food restaurants, and convenience stores were more accessible around schools than around residences, as shown by shorter walking distances to and higher densities of each type of food establishment in school neighbourhoods. It was shown that attending a school with a higher density of fast food restaurants/convenience stores than supermarket/specialty store gives a greater likelihood of consuming SSB, after adjusting for individual and contextual covariates.

Although we failed to find associations with specific characteristics of the built environment, this finding suggests that SSB consumption may be influenced by a dense urban environment enclosing a set of characteristics which globally offers a more important variety of SSB sources proximal to a school, where the street network is considered walkable and possibly more attractive for pedestrians where the presence of vegetation is important. This finding is particularly important because it suggests that contextual influences are not necessarily causal links on individuals' behaviors but rather act as risk regulators which facilitated or constrained individuals' choices rather than causing them directly [52] and that global contextual measurements are sometime more efficient to capture the individual-environment dynamics for specific context [75]. In the case of Sherbrooke, for example, the lower risk of SSB consumption by students going to a school located in a low urban density environment may be due to a more important proportion of students taking a school bus to travel between home and school and thus is less solicited by the commercial offer of SSB in the school vicinity, a situation that might not be true elsewhere.

These research findings exposed a significant variation in child's SSB consumption between schools and revealed the important role of the socioeconomic and built environment in the surrounding environment. They are supported by a strong methodological setup. Strengths of this study include the high participation rate of households (79\%) and primary schools (100\%), allowing generalizability of the findings for the studied area and a possible contribution to elaborate public health or urban planning interventions. The use of multilevel analysis controlled for the shared variance of SSB consumption between schools, but also to analyse its importance as compared to individual-level influences. Using global measurements of the built environment allowed detecting the combined influence of some characteristics that were not individually associated with SSB. This finding clearly supports the hypothesis that contextual influences on child's behaviors are not necessarily direct and causal. The individual-environment dynamics are complex to measure; it may be more helpful for research and intervention to consider contextual influences as the conditions that regulate exposure probabilities to behaviors that lead to disease [52]. Although global contextual measurement may be more difficult to interpret, they may be the more efficient way to explain the contextual influences and may help to avoid finding no relationship where one actually exists (type 2 error).

A few limitations need to be kept in mind for the interpretation of the results. The cross-sectional design of this study does not ultimately reveal the direction of the associations between SSB and environmental factors. Also, although questionnaires were anonymous and confidential, data was reported by the parent instead of directly by the child, introducing possible information bias. No validated FrenchCanadian questionnaire on the frequency of SSB consumption currently exists, but since the measurement we used was adapted from the two important governmental surveys 
(CHMS and SHSCT), little doubts remain on its reliability [76]. Data pertaining to the characteristics of home environment (composition of household, socioeconomic status) or the distance between home and school was not collected; this information would have helped to better understand the environments to which students are exposed while on their way to school and permitted controlling for confounding effects of parents' socioeconomic status. Finally, while there is a possible interaction between SSEI and the urban density, it was not statistically feasible to integrate both indicators in the statistical model because of multicollinearity. A larger number of schools (e.g., 100 schools or more) would have allowed testing this interaction in a multilevel model, but we were constrained by the actual number of schools in the area $(n=39)$.

\section{Conclusion}

In Canada, approximately $10 \%$ of children are currently obese. Given the immediate and long term consequences of childhood obesity, it is of prime importance to better understand the multiple levels of influence that characterize the obesity epidemic, including the social and built environments. As school settings are among the most important environments to which children are exposed to, estimating their impact on dietary choices is essential to understand how the imbalance between energy intake and energy expenditure occurs. Only a few studies have investigated the role of nonresidential environments. To our knowledge, this is the first study to investigate this relationship for an exhaustive set of school at the regional level. Our results revealed important variations of children SSB consumption between Sherbrooke's schools according to the environmental characteristics in its vicinity. These findings are important for health and place studies since they highlight the influence of the school's vicinity taken globally, rather than direct causal links with specific characteristics. Thus it supports theories proposing that dietary behaviors are a result of complex interactions between biological, social, and environmental factors [26]. Since all Sherbrooke's schools participated in the survey, results may be directly used by local and regional stakeholders aiming to plan an intervention regarding schools proximal built environment.

\section{Disclosure}

Institutions where the work was performed are Laval University, Graduate School of Land Management and Regional Planning, 2325 Rue des Bibliothèques, Quebec, QC, Canada GIV 0A6; University of Sherbrooke, Faculty of Physical Activity Sciences, 2500 Boulevard de l'Université, Sherbrooke, QC, Canada J1K 2R1; and Evaluation Platform on Obesity Prevention, 2725 Chemin Sainte-Foy, Quebec, QC, Canada G1V 4G5.

\section{Competing Interests}

The authors declare that they have no competing interests.

\section{References}

[1] World Health Organization (WHO), "Obesity and overweight," Fact Sheet N॰311, 2011, http://www.who.int/mediacentre/factsheets/fs311/en/.

[2] S. A. Cunningham, M. R. Kramer, and K. M. V. Narayan, "Incidence of childhood obesity in the United States," The New England Journal of Medicine, vol. 370, no. 5, pp. 403-411, 2014.

[3] Health and Social Care Information Centre, Statistics on Obesity, Physical Activity and Diet: England 2014, HSCIC, Leeds, UK, 2014.

[4] K. C. Roberts, M. Shields, M. de Groh, A. Aziz, and J.-A. Gilbert, "Overweight and obesity in children and adolescents: results from the 2009 to 2011 Canadian Health Measures Survey," Health Reports, vol. 23, no. 3, pp. 37-41, 2012.

[5] S. A. Cunningham and M. Zavodny, "Does the sale of sweetened beverages at school affect children's weight?" Social Science \& Medicine, vol. 73, no. 9, pp. 1332-1339, 2011.

[6] Active Healthy Kids Canada, Is Canada in the Running? The 2014 Active Healthy Kids Canada Report Card on Physical Activity for Children and Youth, Active Healthy Kids Canada, Toronto, Canada, 2014.

[7] WHO, Global Recommendations on Physical Activity for Health, WHO, Geneva, Switzerland, 2010.

[8] R. M. Barros, E. J. Silver, and R. E. K. Stein, "School recess and group classroom behavior," Pediatrics, vol. 123, no. 2, pp. 431436, 2009.

[9] A. R. Cooper, L. B. Andersen, N. Wedderkopp, A. S. Page, and K. Froberg, "Physical activity levels of children who walk, cycle, or are driven to school," American Journal of Preventive Medicine, vol. 29, no. 3, pp. 179-184, 2005.

[10] S. Le Menestrel and D. F. Perkins, "An overview of how sports, out-of-school time, and youth well-being can and do intersect," New Directions for Youth Development, vol. 2007, no. 115, pp. 1325, 2007.

[11] Institute of Medicine (IOM), Accelerating Progress in Obesity Prevention: Solving the Weight of the Nation, The National Academies Press, Washington, DC, USA, 2012.

[12] M. Verloigne, W. Van Lippevelde, L. Maes, J. Brug, and I. De Bourdeaudhuij, "Family- and school-based correlates of energy balance-related behaviours in 10-12-year-old children: a systematic review within the ENERGY (European Energy balance Research to prevent excessive weight Gain among Youth) project," Public Health Nutrition, vol. 15, no. 8, pp. 13801395, 2012.

[13] M. M. Fernandes, "The effect of soft drink availability in elementary schools on consumption," Journal of the American Dietetic Association, vol. 108, no. 9, pp. 1445-1452, 2008.

[14] A. Naska, V. Bountziouka, and A. Trichopoulou, "Soft drinks: time trends and correlates in twenty-four European countries. A cross-national study using the DAFNE (Data Food Networking) databank," Public Health Nutrition, vol. 13, no. 9, pp. 1346-1355, 2010.

[15] A. Pan and F. B. Hu, "Effets satiétogènes des sucres: différences entre boissons et aliments solides," Obésité, vol. 6, no. 4, pp. 206211, 2011.

[16] J. Reedy and S. M. Krebs-Smith, "Dietary sources of energy, solid fats, and added sugars among children and adolescents in the United States," Journal of the American Dietetic Association, vol. 110, no. 10, pp. 1477-1484, 2010.

[17] C. L. Ogden, B. K. Kit, M. D. Carroll, and S. Park, "Consumption of sugar drinks in the United States, 2005-2008," in NCHS Data 
Brief, p. 8, National Center for Health Statistics, Hyattsville, Md, USA, 2011.

[18] Y. C. Wang, S. N. Bleich, and S. L. Gortmaker, "Increasing caloric contribution from sugar-sweetened beverages and 100\% fruit juices among US children and adolescents, 1988-2004," Pediatrics, vol. 121, no. 6, pp. e1604-e1614, 2008.

[19] V. S. Malik, W. C. Willett, and F. B. Hu, "Sugar-sweetened beverages and BMI in children and adolescents: reanalyses of a meta-analysis," The American Journal of Clinical Nutrition, vol. 89, no. 1, pp. 438-439, 2009.

[20] V. S. Malik, B. M. Popkin, G. A. Bray, J.-P. Després, W. C. Willett, and F. B. Hu, "Sugar-sweetened beverages and risk of metabolic syndrome and type 2 diabetes: a meta-analysis," Diabetes Care, vol. 33, no. 11, pp. 2477-2483, 2010.

[21] K. Van Der Horst, A. Oenema, I. Ferreira et al., "A systematic review of environmental correlates of obesity-related dietary behaviors in youth," Health Education Research, vol. 22, no. 2, pp. 203-226, 2007.

[22] F. Harrison and A. P. Jones, "A framework for understanding school based physical environmental influences on childhood obesity," Health \& Place, vol. 18, no. 3, pp. 639-648, 2012.

[23] R. Pabayo, J. C. Spence, N. Cutumisu, L. Casey, and K. Storey, "Sociodemographic, behavioural and environmental correlates of sweetened beverage consumption among pre-school children," Public Health Nutrition, vol. 15, no. 8, pp. 1338-1346, 2012.

[24] B. Swinburn and G. Egger, "Preventive strategies against weight gain and obesity," Obesity Reviews, vol. 3, no. 4, pp. 289-301, 2002.

[25] C. Fung, S. Kuhle, C. Lu et al., "From 'best practice' to 'next practice': the effectiveness of school-based health promotion in improving healthy eating and physical activity and preventing childhood obesity," International Journal of Behavioral Nutrition and Physical Activity, vol. 9, article 27, 2012.

[26] K. Glanz, J. F. Sallis, B. E. Saelens, and L. D. Frank, "Healthy nutrition environments: concepts and measures," American Journal of Health Promotion, vol. 19, no. 5, pp. 330-333, 2005.

[27] J. F. Sallis and K. Glanz, "The role of built environments in physical activity, eating, and obesity in childhood," The Future of Children, vol. 16, no. 1, pp. 89-108, 2006.

[28] J. F. Sallis and K. Glanz, "Physical activity and food environments: solutions to the obesity epidemic," The Milbank Quarterly, vol. 87, no. 1, pp. 123-154, 2009.

[29] M. M. Wall, N. I. Larson, A. Forsyth et al., "Patterns of obesogenic neighborhood features and adolescent weight: a comparison of statistical approaches," American Journal of Preventive Medicine, vol. 42, no. 5, pp. e65-e75, 2012.

[30] S. T. Leatherdale, T. Pouliou, D. Church, and E. Hobin, "The association between overweight and opportunity structures in the built environment: a multi-level analysis among elementary school youth in the PLAY-ON study," International Journal of Public Health, vol. 56, no. 3, pp. 237-246, 2011.

[31] T. T. Huang, A. Drewnosksi, S. Kumanyika, and T. A. Glass, "A systems-oriented multilevel framework for addressing obesity in the 21st century," Preventing Chronic Disease, vol. 6, no. 3, p. A82, 2009.

[32] G. F. Dunton, J. Kaplan, J. Wolch, M. Jerrett, and K. D. Reynolds, "Physical environmental correlates of childhood obesity: a systematic review," Obesity Reviews, vol. 10, no. 4, pp. 393-402, 2009.

[33] P. M. Anderson and K. F. Butcher, "Childhood obesity: trends and potential causes," The Future of Children, vol. 16, no. 1, pp. 19-45, 2006.
[34] C. B. Ebbeling, D. B. Pawlak, and D. S. Ludwig, "Childhood obesity: public-health crisis, common sense cure," The Lancet, vol. 360, no. 9331, pp. 473-482, 2002.

[35] D. S. Ludwig, K. E. Peterson, and S. L. Gortmaker, "Relation between consumption of sugar-sweetened drinks and childhood obesity: a prospective, observational analysis," The Lancet, vol. 357, no. 9255, pp. 505-508, 2001.

[36] H. Patrick and T. A. Nicklas, "A review of family and social determinants of children's eating patterns and diet quality," Journal of the American College of Nutrition, vol. 24, no. 2, pp. 83-92, 2005.

[37] C. Ni Mhurchu, S. Vandevijvere, W. Waterlander et al., "Monitoring the availability of healthy and unhealthy foods and nonalcoholic beverages in community and consumer retail food environments globally," Obesity Reviews, vol. 14, supplement 1, pp. 108-119, 2013.

[38] A. L. Pearson, P. de Latour, G. Kemp et al., "Understanding differences in access to water fountains and sugar-sweetened beverages in children's environments: a pilot study in high and low deprivation neighbourhoods," Health \& Place, vol. 30, pp. 94-97, 2014.

[39] L. C. Mâsse, J. E. de Niet-Fitzgerald, A. W. Watts, P.-J. Naylor, and E. M. Saewyc, "Associations between the school food environment, student consumption and body mass index of Canadian adolescents," International Journal of Behavioral Nutrition and Physical Activity, vol. 11, no. 1, article 29, 2014.

[40] R. Huang and K. Kiesel, "Does limited access at school result in compensation at home? The effect of soft drink bans in schools on purchase patterns outside of schools," European Review of Agricultural Economics, vol. 39, no. 5, pp. 797-820, 2012.

[41] N. Larson and M. Story, "A review of snacking patterns among children and adolescents: what are the implications of snacking for weight status?" Childhood Obesity, vol. 9, no. 2, pp. 104-115, 2013.

[42] J. Williams, P. Scarborough, A. Matthews et al., "A systematic review of the influence of the retail food environment around schools on obesity-related outcomes," Obesity Reviews, vol. 15, no. 5, pp. 359-374, 2014.

[43] D. R. Taber, J. F. Chriqui, L. M. Powell, and F. J. Chaloupka, "Banning all sugar-sweetened beverages in middle schools: reduction of in-school access and purchasing but not overall consumption," Archives of Pediatrics and Adolescent Medicine, vol. 166, no. 3, pp. 256-262, 2012.

[44] G. C. Grimm, L. Harnack, and M. Story, "Factors associated with soft drink consumption in school-aged children," Journal of the American Dietetic Association, vol. 104, no. 8, pp. 12441249, 2004.

[45] Lavallee, J. Aubin, N. Audet, and P. Berthiaume, "Enquête sociale et de santé auprès des enfants et des adolescents québécois 1999," in Collection la Santé et le Bien-être, p. 520, Institut de la statistique du Québec, Québec, Canada, 2002.

[46] Statistics Canada, Enquête sur la Santé Dans les Collectivités Canadiennes (cycle 2.2)-Nutrition (2004)—Questionnaire, 2005.

[47] P. Morin, K. Demers, S. Turcotte, and L. Mongeau, "Association between perceived self-efficacy related to meal management and food coping strategies among working parents with preschool children," Appetite, vol. 65, pp. 43-50, 2013.

[48] H.-S. Lee, S.-O. Kwon, and Y. Lee, "Weight status and dietary factors associated with sugar-sweetened beverage intake among Korean children and adolescents-Korea National Health and 
Nutrition Examination Survey, 2008-2011," Clinical Nutrition Research, vol. 2, no. 2, pp. 135-142, 2013.

[49] N. Martin-Calvo, M.-A. Martínez-González, M. Bes-Rastrollo et al., "Sugar-sweetened carbonated beverage consumption and childhood/adolescent obesity: a case-control study," Public Health Nutrition, vol. 17, no. 10, pp. 2185-2193, 2013.

[50] M. Zheng, A. Rangan, N. J. Olsen et al., "Sugar-sweetened beverages consumption in relation to changes in body fatness over 6 and 12 years among 9-year-old children: the European Youth Heart Study," European Journal of Clinical Nutrition, vol. 68, no. 1, pp. 77-83, 2014.

[51] T. K. Richmond, J. L. Spadano-Gasbarro, C. E. Walls et al., "Middle school food environments and racial/ethnic differences in sugar-sweetened beverage consumption: findings from the Healthy Choices study," Preventive Medicine, vol. 57, no. 5, pp. 735-738, 2013.

[52] T. A. Glass and M. J. McAtee, "Behavioral science at the crossroads in public health: extending horizons, envisioning the future," Social Science \& Medicine, vol. 62, no. 7, pp. 1650-1671, 2006.

[53] J. Maas, R. A. Verheij, P. P. Groenewegen, S. De Vries, and P. Spreeuwenberg, "Green space, urbanity, and health: how strong is the relation?" Journal of Epidemiology and Community Health, vol. 60 , no. 7, pp. 587-592, 2006.

[54] A. Forsyth, D. Van Riper, N. Larson, M. Wall, and D. NeumarkSztainer, "Creating a replicable, valid cross-platform buffering technique: the sausage network buffer for measuring food and physical activity built environments," International Journal of Health Geographics, vol. 11, article 14, 2012.

[55] B. Lalonde, A. Lebel, and É. Robitaille, Indicateurs Géographiques Caractérisant l'Environnement Bâti et l'Accessibilité Aux Services à Proximité des é Coles du Québec. Rapport Méthodologique et Portrait des Régions, Plateforme d'Évaluation en Prévention de i'Obésité, Québec, Canada, 2014.

[56] H. L. Beyer, "Geospatial Modelling Environment," Spatial Ecology, 2012.

[57] I. Yamada, B. B. Brown, K. R. Smith, C. D. Zick, L. KowaleskiJones, and J. X. Fan, "Mixed land use and obesity: an empirical comparison of alternative land use measures and geographic scales," Professional Geographer, vol. 64, no. 2, pp. 157-177, 2012.

[58] E. Leslie, N. Coffee, L. Frank, N. Owen, A. Bauman, and G. Hugo, "Walkability of local communities: using geographic information systems to objectively assess relevant environmental attributes," Health and Place, vol. 13, no. 1, pp. 111-122, 2007.

[59] É. Robitaille, D. Comtois, and B. Lasnier, "Potentiel piétonnier des quartiers et mode de transport pour aller au travail : le cas des RMR du Québec," Cahiers de Géographie du Québec, vol. 55, no. 156, pp. 429-448, 2011.

[60] L. D. Frank, T. L. Schmid, J. F. Sallis, J. Chapman, and B. E. Saelens, "Linking objectively measured physical activity with objectively measured urban form: findings from SMARTRAQ," American Journal of Preventive Medicine, vol. 28, no. 2, supplement 2, pp. 117-125, 2005.

[61] S. C. J. Cummins, L. McKay, and S. MacIntyre, "McDonald's restaurants and neighborhood deprivation in Scotland and England," American Journal of Preventive Medicine, vol. 29, no. 4, pp. 308-310, 2005.

[62] A. Lebel, Y. Kestens, R. Pampalon, M. Thériault, M. Daniel, and S. V. Subramanian, "Local context influence, activity space, and foodscape exposure in two Canadian metropolitan settings: is daily mobility exposure associated with overweight?" Journal of Obesity, vol. 2012, Article ID 912645, 9 pages, 2012.
[63] Statistics Canada, Educational Portrait of Canada, 2006 Census, Minister of Industry, Ottawa, Canada, 2008.

[64] Ministère de l'Éducation, La Carte de la Population Scolaire et les Indices de Défavorisation, Ministère de l'Éducation, Québec, Canada, 2003.

[65] W. J. Browne, MCMC Estimation in MLwiN, v2.25, Centre for Multilevel Modelling: University of Bristol, 2012.

[66] Y. Kestens, A. Lebel, B. Chaix et al., "Association between activity space exposure to food establishments and individual risk of overweight," PLoS ONE, vol. 7, no. 8, Article ID e41418, pp. 1-13, 2012.

[67] J. Merlo, B. Chaix, H. Ohlsson et al., "A brief conceptual tutorial of multilevel analysis in social epidemiology: using measures of clustering in multilevel logistic regression to investigate contextual phenomena," Journal of Epidemiology and Community Health, vol. 60, no. 4, pp. 290-297, 2006.

[68] D. J. Spiegelhalter, N. G. Best, B. P. Carlin, and A. van der Linde, "Bayesian measures of model complexity and fit," Journal of the Royal Statistical Society-Series B: Statistical Methodology, vol. 64, no. 4, pp. 583-639, 2002.

[69] S. V. Subramanian, K. Jones, A. Kaddour, and N. Krieger, "Revisiting Robinson: the perils of individualistic and ecologic fallacy," International Journal of Epidemiology, vol. 38, no. 2, pp. 342-360, 2009.

[70] N. Lien, M. M. Van Stralen, O. Androutsos et al., "The school nutrition environment and its association with soft drink intakes in seven countries across Europe-the ENERGY project," Health and Place, vol. 30, pp. 28-35, 2014.

[71] M. A. Carter and L. Dubois, "Neighbourhoods and child adiposity: a critical appraisal of the literature," Health \& Place, vol. 16, no. 3, pp. 616-628, 2010.

[72] L. M. Koehly and A. Loscalzo, "Adolescent obesity and social networks," Preventing Chronic Disease, vol. 6, no. 3, article A99, 2009.

[73] J. H. Freeland-Graves and S. Nitzke, "Position of the Academy of Nutrition and Dietetics: total diet approach to healthy eating," Journal of the Academy of Nutrition and Dietetics, vol. 113, no. 2, pp. 307-317, 2013.

[74] A. van Hulst, T. A. Barnett, L. Gauvin et al., "Associations between children's diets and features of their residential and school neighbourhood food environments," Canadian Journal of Public Health, vol. 103, supplement 3, pp. S48-S54, 2012.

[75] C. Black, G. Moon, and J. Baird, "Dietary inequalities: what is the evidence for the effect of the neighbourhood food environment?" Health \& Place, vol. 27, pp. 229-242, 2014.

[76] C. Lavallée, Enquête Sociale et de Santé Auprès des Enfants et des Adolescents Québécois: Volet Nutrition, Institut de la statistique du Québec, Québec, Canada, 2004. 


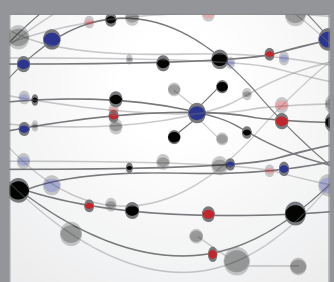

The Scientific World Journal
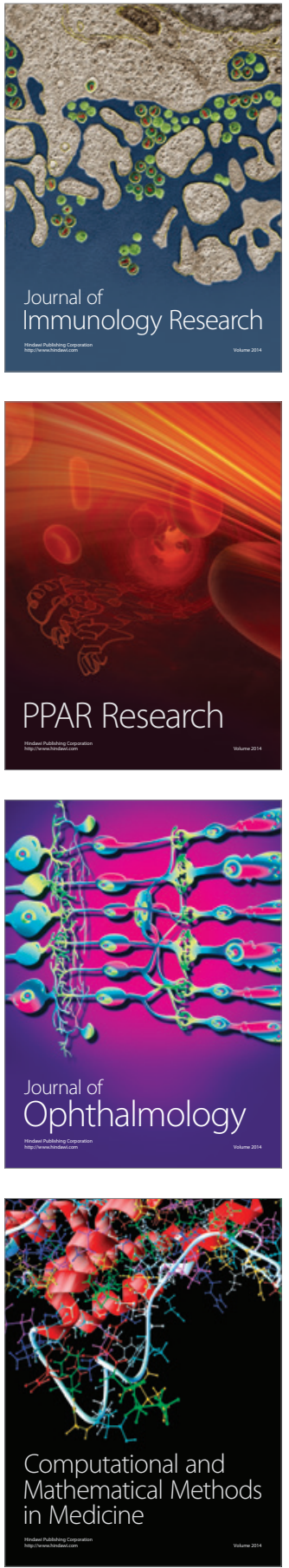

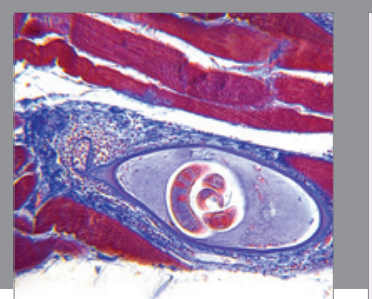

Gastroenterology Research and Practice

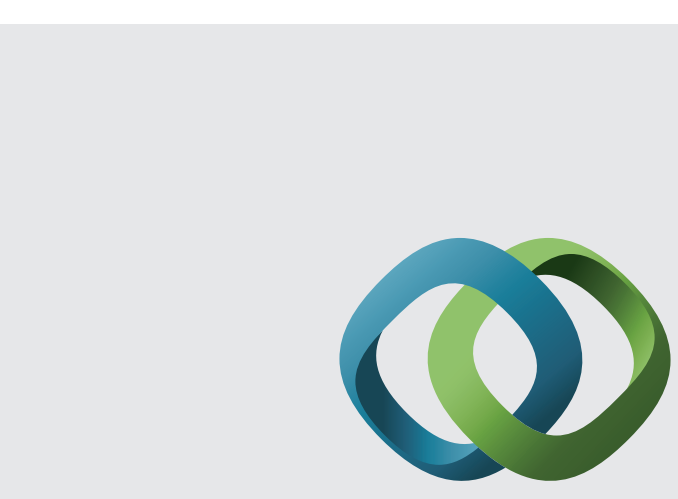

\section{Hindawi}

Submit your manuscripts at

http://www.hindawi.com
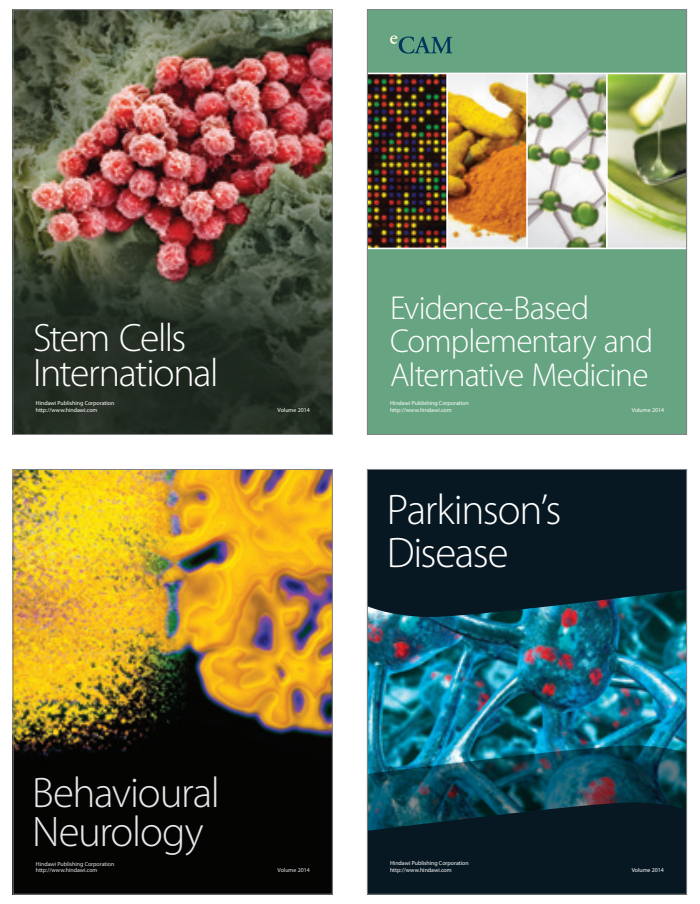
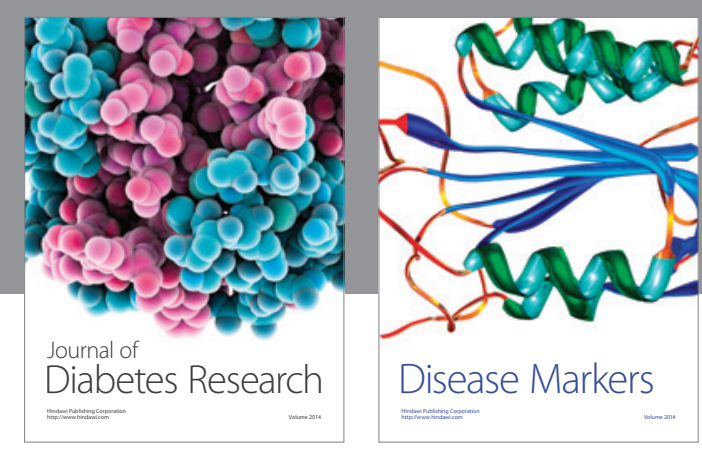

Disease Markers
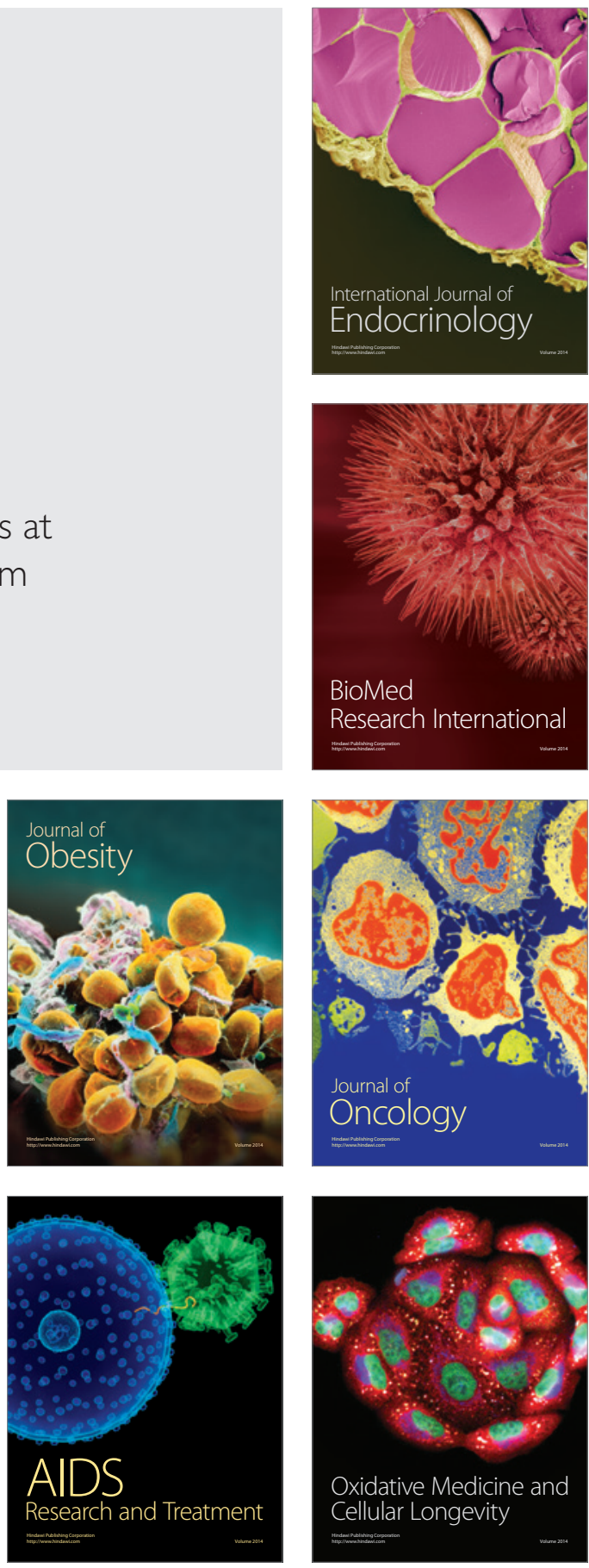